\title{
LUGARES CELESTES \\ DEL NEOPLATONISMO MEDIEVAL ${ }^{1}$
}

\author{
ALFONS PUIGARNAU \\ Universidad Internacional de Cataluña
}

\begin{abstract}
RESUMEN: Durante la historia de la cultura medieval, desde sus orígenes tardoantiguos hasta su entrada en el período del humanismo, el sistema del pensamiento neoplatónico cristaliza en distintas manifestaciones filosóficas, teológicas, artísticas y literarias. Uno de los grandes temas de esta estructura teórica es la referencia a un mundo astral, sideral o celeste, que aparece testimoniada en la epigrafía, el arte, la música o la poesía latina medieval. En este artículo se postulan Lugares Celestes como la Muerte, el Viaje, el Juicio y la Divinización en los que esta epistemología del tránsito a lo celeste encuentra sólidas bases históricas y hermenéuticas.
\end{abstract}

PALABRAS CLAVE: Lugares celestes, Edad Media, Neoplatonismo, Patrística latina, Arte Románico, Literatura medieval, Juan Escoto Eriúgena.

\section{Caelestia of Mediaeval Neoplatonism}

ABSTRACT: Between the late-Antiquity period and the development of the Western Humanism in Europe the system of ideas called Neoplatonic Thought influences different interdisciplinary areas of knowledge. Philosophy, theology, art and literature register a particular development of the reference to the transition of visible into invisible in the aesthetic and historical manifestations provided by inscriptions, art, music and Latin poetry. In this paper so-called Caelestia like Death, Voyage, Judgement and Divinisation are postulated and theorised as different methodological possibilities where a peculiar epistemology of Transition to a certain «beyond» can have solid historical and interpretative basis.

KEY WORDS: Caelestia, Middle Ages, Neoplatonism, Latin Patristics, Romanesque Art, Medieval Texts, John Scottus Eriugena.

Icare, per superos qui raptus et aera, donec

In mare praecipitem cera liquata daret,

Nunc te cera eadem, fervensque resuscitat ignis,

Exemplo ut doceas dogmata certa tuo.

Astrologus caveat quicquam praedicere: praeceps

Nam cadet impostor dum super astra volat.

Alciato, Emblemata, 104

Tal vez el estudio del cuerpo doctrinal del neoplatonismo se asocia, en primera instancia, a la disciplina teológica. Este prejuicio disciplinar no necesariamente actúa en detrimento de la fuerza con que los neoplatónicos abordaron los problemas filosóficos, morales o incluso científicos. En buena parte, los escritos de Plotino, de sus discípulos y comentadores son un desarrollo teórico

1 Texto íntegro de la conferencia del autor impartida en la I Jornada Metodológica celebrada en Madrid el 24 de enero de 2013 a raíz del encuentro de los miembros del equipo de investigación coordinado por la Dra. María del Mar Graña Cid «Visiones del Cielo: espiritualidad, política y cultura» con sede y financiación en la Facultad de Teología de la Universidad Pontificia de Comillas, Ref. 109011103. 
de una ontología de la esencia divina con características teológicas muy particulares. El neoplatonismo es una tarea de liberación del alma y de la «máxima asimilación entre Dios y el hombre ${ }^{2}$. Al mismo tiempo, de ser el neoplatonismo una filosofía, estaría claramente en la línea del estoicismo de la Escuela a la que perteneció Plotino: siguiendo esta línea filosófica, ser mejor consistiría en liberarse de la materia y, en resumidas cuentas, del propio cuerpo.

El neoplatonismo contiene también trazas de una filosofía política, desde el momento en que Plotino, amigo personal del Emperador Galieno y su esposa Salonina, pretendió fundar Platonópolis, una ciudad-convento donde practicar la teoría neoplatónica y conseguir una determinada felicidad filosófica y política. A la vez, este neoplatonismo propone también una cierta filosofía del arte, desde el momento en que el establecimiento de arquetipos de la realidad y la propia noción de imitación entrañan una propuesta de la representación artística del mundo.

Al hablar aquí de neoplatonismo sólo me refiero a los autores platónicos inspirados en Plotino (205-270) y dejo, deliberadamente, a los miembros de la Academia de Platón y a los medio-platónicos, esto es, platónicos del período de la Roma imperial anteriores a Plotino. Esto no impide la continuidad entre el platonismo medio y el neoplatonismo al que me referiré a lo largo de estas páginas. En realidad, todo neoplatonismo contiene, primero, una propuesta de divinización del hombre y, sólo más tarde, una divinización del arte, la política, el mundo. Precisamente, la escatología neoplatónica defiende la separación del alma de lo material y la idea de que la fuerza del amor es la que conduce a la felicidad ${ }^{3}$. El tema básico de esta filosofía es la ascensión del alma, lo cual significa un retorno o regreso a uno mismo: la $\alpha v \alpha \chi \omega \rho \eta \sigma ı \varsigma ~ \varepsilon ı \varsigma ~ \varepsilon \alpha v \tau o v$ que practican ascetas y monjes medievales. El hombre se diviniza, preparándose para divinizar todo lo demás.

Lógicamente, algunos aspectos de esta dinámica iban a encajar perfectamente con la teología cristiana primero y, sólo más tarde, con una cosmovisión más amplia típica del cristianismo, que iba a afectar a las cosas y los hombres en Occidente durante más de mil años de historia. El cristianismo asume, a través de Plotino y el gnosticismo, las reminiscencias platónicas de algunos axiomas místicos y ascéticos: la virtud como principio purificador que asimila a la divinidad, la transmigración del alma ${ }^{4}$, la teoría epistemológica de la re-

2 Teeteto 176 176b, frase de la que los neoplatónicos hicieron su consigna o leimotiv.

3 Porfirio, Uita Plotini, 23.

4 La confianza en la inmortalidad del alma ha sido descrita como uno de los pilares del Platonismo y es ya conocida la defensa de Sócrates en el Fedón de Platón (81a9; 114c2 ss.). No obstante, los comentarios al diálogo por parte de Olimpiodoro (c. 495-570) y Damascio (c. 458-más tarde de 538) ofrecen una perspectiva especial en relación al destino último del alma, que influiría en la asimilación de este tema por parte del cristianismo. Cuando san Agustín comenta la obra desaparecida de Porfirio (De regressu animae) dice de él que mantenía que al menos el alma del filósofo debería permanecer para siempre en el Intelecto del Padre escapando así del ciclo del ascenso y descenso a la generación (o reencarnación): quod mundatam ab omnibus malis animam et cum Patre constitutam numquam iam mala mundi huius passuram esse confectus est (De civitate Dei X.30). Agustín observa que Porfirio formula 
miniscencia, el Bien como fin de una ascensión gradual y escalonada, la visión mental que culmina el empeño moral e intelectual y que se presenta como una revelación, como una unión mística basada en el principio de afinidad y, finalmente, el amor como impulso inicial de todo el proceso. Todos estos temas de raigambre platónica son típicos de la Platonópolis de Plotino y, posteriormente, van a reaparecer como definición de la ciudad ideal celeste de la hagiografía ${ }^{5}$.

Pero el neoplatonismo tiene una virtualidad de la que otros sistemas de pensamiento no disfrutan, al poder ser objeto y sujeto del análisis filosófico al mismo tiempo. Sin ir más lejos, el músico alemán Richard Wagner (1813-1883) plantea su esquema del Parsifal utilizando la imagen del claro de un bosque, en un recurso compositivo típico del neoplatonismo ${ }^{6}$; el historiador del arte, también alemán, Aby Warburg (1866-1929), se vale del sistema neoplatónico para una hermenéutica del renacimiento italiano; o, en esta serie de ejemplos que podría ser más larga, Erwin Panofsky (1892-1968), también historiador del arte y alemán emigrado a América, sustituye el idealismo alemán por el neoplatonismo como sistema hermenéutico para aplicar su método iconológico ${ }^{7} \mathrm{al}$ estudio de la obra de Alberto Durero (1943) ${ }^{8}$.

Este texto es un análisis de algunas expresiones que el arte y la literatura de época medieval ofrecen, directamente relacionadas con uno de los lugares preferidos de la cultura neoplatónica del occidente cristiano: las visiones del Cielo. La migración del alma humana hacia las regiones celestes constituye un tema poco analizado desde el arte y la filosofía, algo más tratado por la teología (escatológica) y la literatura (el vuelo sideral) y muy poco por la ciencia

una doctrina platónica que rivaliza con el concepto cristiano de eterna bienaventuranza de los santos. Cf. Gertz, Sebastian Ramon Philipp. Death and immortality in late Neoplatonism: studies on the ancient commentaries on Plato's Phaedo. Vol. 12. Leiden, Brill, 2011, p. 187, y notas 26-26. También Jámblico (245-325), citado por Damascio, trata de este tema en "Sobre la migración del alma desde el cuerpo". Cf. Dam. I.548 y los comentarios de Leendert Gerrit Westerink en: "Damascius, Commentary on the Phaedo", The Greek Commentaries on Plato's Phaedo, vol. 2, Amsterdam, North-Holland, 1977. Lógicamente, la doctrina de la reencarnación del alma humana nunca ha sido aceptada por el Magisterio de la Iglesia (Cf. por ejemplo: Concilio Vaticano II, Const. dogm. Lumen Gentium, nn. 48-51; Const. past. Gaudium et Spes, nn. 18, 39.Catecismo de la Iglesia Católica, nn. 668-682; 988-1060.

5 El emperador Galieno estimaba tanto a Plotino que se dice que accedió a la petición de éste de refundar la ciudad de los filósofos que se regía por las leyes de Platón y se llamaba Platonópolis (Porfirio, Vita Plotini, 12). Puede ser que esta leyenda esté en el origen del concepto de ciudad ideal representado por la Ciudad de Dios agustiniana o por la Jerusalén celeste y sus proyecciones terrenales.

6 «Selva umbría y severa, pero no lóbrega. Hacia el centro, un claro»: WAGNER, Richard. Parsifal (Libreto). Libros del Innombrable, 1999: 76). El subrayado es nuestro.

7 Cf. Ferretti, S. Cassirer, Panofsky, and Warburg: symbol, art, and history. Yale University Press, 1989.

8 Sobre esto, ver la obra: Holly, Michael Ann. Panofsky and the foundations of art history. Ithaca, NY: Cornell University Press, 1985 y su reseña en: Levi, Albert William. «Kunstgeschichte als Geistesgeschichte: The lesson of Panofsky.» Journal of Aesthetic Education (1986): 79-83. 
(astrología, pero también astronomía). Es un tema neoplatónico que, además, se puede analizar valiéndose del neoplatonismo considerado como hermenéutica válida aquí y ahora, donde el arte, la arqueología, la archivística, la musicología o la poesía son testimonios de un sistema cultural más amplio.

Se trata, en definitiva, de buscar la correspondencia, en el sistema de las letras y de las artes, entre el pensamiento, la palabra y la imagen, donde lo celeste, las visiones del Cielo, solicitan una cosmovisión unitaria y la unanimidad cultural típica de los grandes sistemas de pensamiento. Tratar de los lugares del cielo como episodios filosóficos - la Muerte, el Viaje, el Juicio y la Divinización o Retorno del alma- es proponer, en realidad, el neoplatonismo como base de todo el sistema simbólico que pertenece por derecho propio al imaginario filosófico de la Edad Media europea.

\section{Primer lugar: la Muerte}

El siglo XII, adormecido por un pasado convulsionado y turbulento, revive la metafísica neoplatónica en convivencia con el amanecer del aristotelismo en las universidades europeas ${ }^{9}$. Es extraña la convivencia entre la Antigüedad clásica que llega contaminada, o matizada, por la bella rareza de la filosofía árabe ${ }^{10}$. Mientras se concibe la catedral gótica en algunos centros urbanos, en zonas rurales de montaña, o en valles inhóspitos, artistas y pensadores itinerantes repiten incansablemente sus fórmulas iconográficas, filosóficas y teológicas. La teología afirmativa convive con la negativa, la ascética con la mística ${ }^{11}$.

Veamos, en este contexto, un primer lugar celeste en el arte que remite al gran tema del pensamiento neoplatónico medieval. Hay en el Museo Diocesano de Gerona una placa ${ }^{12}$ con el llamado «Epitafio anónimo de Ampurias» ${ }^{13}$. Tiene una inscripción singular: cuiusdam corpus defunctum quem Deus, fautor omnipotens, super astra beavit ${ }^{14}$. Trata de un tema fúnebre, es cierto. Podría

9 Cf. Severino Boecio como conciliador de Platón y Aristóteles en: Minnis, Alastair J. Chaucer's Boece and the medieval tradition of Boethius. Vol. 18. Boydell \& Brewer, 1993.

10 Cf. BuRnett, Сн. "Arabic into Latin: the reception of Arabic philosophy into Western Europe.» The Cambridge Companion to Arabic Philosophy (2005): 370-404.

11 Hart, Kevin. The trespass of the sign: Deconstruction, theology, and philosophy. Vol. 13. Fordham University Press, 2000.

12 Fernández, S. La epigrafía latina medieval en los condados catalanes (815-circ. 1150). No. 11. AC Castellum, 2003. Apéndice epigráfico n. 28: 311-312.

13 El epitafio en cuestión fue atribuido por Almagro Basch (Almagro Basch, Martín. Las inscripciones ampuritanas, griegas, ibéricas y latinas. Publ. por el Departamento de Barcelona del Instituto Rodrigo Caro de arqueología del CS de IC, 1952: 235-236) a las ruinas de Ampurias, quizá procedente de alguna de la iglesias de la zona. Marqués Casanovas la dio como procedente de la iglesia de Sant Martí de Sacosta, en Girona, sin aducir las razones que le llevaron a tal atribución (MARQuès, J. «Girona Vella.» (1979): 76).

14 Almagro Basch, Martín Las inscripciones ampuritanas: griegas, ibéricas y latinas. Departamento de Barcelona del Instituto Rodrigo Caro de Arqueología del Consejo Superior de Investigaciones Científicas, 1952: 234-236. MARQuÈs, J. «Girona Vella.» (1979): 76. 
interpretarse sólo en clave soteriológica. Pero ¿qué aspectos de esa expresión super astra (sobre lo celeste), remiten al pensamiento neoplatónico medieval europeo que aquí nos interesa? Más concretamente, ¿cuál es el significado filosófico de un cuerpo al que Dios hace santo por encima de las estrellas (corpus super astra beavit)?

Se ha hablado de que el cristianismo tardoantiguo constituyó un «giro material», a modo de reconfiguración de la relación entre materialidad y significado, que formaba parte de un fenómeno cultural más amplio. En este sentido, la teatralidad, el expresionismo visual o la preferencia por una inmediatez visual están presentes en esta inscripción del siglo XII. Los autores de esta época invocan una imaginación visual que se irá desarrollando con el paso de los siglos, invitando al espectador a "ver» santidad en los cuerpos de sus héroes. En la nueva religión, se da un incremento de la capacidad de «ver más de lo que literalmente hay» en lo objetos o en el imaginario material para entender la propia identidad $^{15}$.

Otro epitafio fúnebre ${ }^{16}$, de Bernat Tallaferro, conde de Besalú ${ }^{17}$, reza en los siguientes términos, ofreciendo otro ejemplo de lugar (corporal) celeste y, con él, de lugar filosófico dentro del sistema del neoplatonismo: «La nobleza, la belleza, el cuerpo, el valor se iluminan con el vástago, al instante florecen y con poco al fin se disuelven. Estos condes aquí enterrados, Bernardo Tallaferro y Guillermo llamado el Gordo, así lo testifican; (...) ¡Que dichosos y coronados reinen sobre los astros! ${ }^{18}$ Aquí hay una obvia referencia a la muerte, pero el cuerpo no es un despojo sino que se mantiene como lugar celeste en virtud de un pensamiento filosófico en relación al ciclo de la vida: la luz que engendra, la juventud que hace florecer, la realidad del tiempo y su disolución, ciertamente. Pero luego siguen reinando (sobre los astros). En este caso, el lugar celeste tiene un significado político más allá de la corporalidad del conde de Besalú. Una corporalidad que, típicamente neoplatónica, es capaz de seguir reinando más allá de las estrellas. En este ejemplo, es el silencio de la muerte corporal la estrategia retórica utilizada para seguir reinando en el más allá ${ }^{19}$.

15 Cf. Adam G. Cooper; The Body in St. Maximus the Confessor: Holy Flesh, Wholly Deified; Oxford Early Christian Studies; Oxford: Oxford University Press, 2005.

16 Fernández, S. La epigrafía latina medieval: 322. Epitafio de Bernardo Tallaferro (Ripoll, Ripollés). S. XII Splendor, forma, caro, virtus, cum germine claro,/ut cito florescunt, modico sic fine liquescunt./3 Hoc duo testantur comites hic qui tumulantur:/Bernardus Taiaferr, Guilelm cognomine crassus;/sed pater infando Rodano fatalia passus./6 Armis, consilio, rebus, fama viguere./ Sumptibus hanc multis ditare domum studere./Unde coronati regnent super astra beati.

17 Ibid,, Apéndice epigráfico n. 40: 322-323.

18 Villanueva, J., y Lorenzo Villanueva, J., Viage literario a las iglesias de España. Vol. 15. Imprenta real, 1803: 66; FitA, Fidel. «Epigrafía romana.» (1883): 40-42; de Molins, ANTonio Elías. Bibliografía histórica de Cataluña: Preliminares, numismática, epigrafía, colecciones diplomáticas, sigilografía. Librería de Victoriano Suárez, 1902: 108-110.

19 En este caso, cf. Poster, C. «Silence as a Rhetorical Strategy in Neoplatonic Mysticism.» Mystics Quarterly (1998): 48-73. 
Como filósofo e historiador, a veces me he preguntado por el significado de una inscripción románica, que los especialistas en arte han explicado sólo de forma ambigua ${ }^{20}$. En ella se utilizan unas palabras parecidas a las del Emblema de Alciato que abre nuestras consideraciones, inspirado en las Metamorfosis de Ovidio: super astra volat ${ }^{21}$. Quisquis super astra levatur. Ad me spem vit(a)e duce $m e . .$. «Cualquiera puede ser elevado a las estrellas» — dice el hexámetro leonino ${ }^{22}$ - Y termina: «Llévame a la esperanza de la vida».

Otra vez trata de ver en esta inscripción el lugar celeste, filosófico y teológico, que el vuelo del alma ocupa en la historia de la filosofía y, tal vez, también en la estética y la filosofía de la cultura. Porque es preciso observar que las conexiones entre patrística e himnología constituyen ejemplos de una metafísica de la luz ${ }^{23}$ que cristaliza en la representación iconográfica de la Ousía; y a la vez importa saber que fue Juan Escoto Eriúgena quien propuso esta denominación -Ousía - como uno de los nombres para denominar la sustancia de Dios. «Pero antes creo que debemos ponderar por qué los nombres que has mencionado, es decir, Esencia, Bondad, Verdad, Justicia, Sabiduría, y otros de este tipo, que no sólo parecen ser divinos, sino los más divinos, y que no parecen significar más que la Divina Substancia o Esencia (...) $»^{24}$.

Estamos, pues, ante otro lugar filosófico del Cielo que, además, es capaz de explicar la geometrización típica de la estética del arte románico. «Si entonces, los cuerpos geométricos, que contemplamos sólo con los ojos del intelecto, y que sólo somos capaces de construir a través de imágenes en nuestra memoria, subsisten en alguna, entonces son naturales, y no hay diferencia entre los cuerpos geométricos y los naturales. Pero si contemplamos los cuerpos geométricos sólo con el intelecto, y si no subsisten en una ousia, son correctamente llamados imaginarios. Luego un cuerpo, para ser un cuerpo, necesita ousia, porque si no la tiene es una mera figura en la imaginación, mientras que la ousia no requiere de un cuerpo porque subsiste en sí misma» ${ }^{25}$. Los cuerpos geométricos los contemplamos sólo con los ojos del intelecto: geometrica corpora solo animo consideramus, dice el Eriúgena ${ }^{26}$. Así será posible, a

20 AA, DD. «La Catalunya Romànica.» (1990), 10: 197-201; vol. 22: 183-185.

21 Las metamorfosis: VIII, 183-235.

22 Cf. Cooper, Charles Gordon. An introduction to the Latin hexameter. Macmillan, 1952.

23 Cf. el texto, ya clásico: McEvoy, J. "The Metaphysics of Light in the Middle Ages.» Philosophical Studies Dublin 26 (1979): 126-145.

24 PL 122, 458D-460B. En la bibliografía es Migne, Patrologia latina.

25 PL 122, 494A: nunc vero, quoniam geometrica corpora solo animo consideramus, in nullaque ousia subsistunt phantastica jure vocantur, naturalia vero corpora propterea naturalia sunt, quoniam in naturalibus suis ousiis, id est essentiis, subsistunt, et sine quibus esse non possunt, ideoque vera sunt; alioquin non in rebus naturalibus, sed sola ratione cogitarentur: profecto datur intelligi, aliud esse corpus, aliud ousian, quoniam corpus aliquando caret ousia, aliquando adhaeret ousiae, ut verum sit, sine qua verum fieri non potest, sed quadam imaginatione figuratum; ousia vero nullo modo corporis indiget, ut sit, quoniam per se ipsam subsistit.

26 PL 122, 493D. 
lo largo de la primera Edad Media, transmitir la idea principal de la Esencia divina, un verdadero lugar celeste del neoplatonismo medieval, directamente relacionado con la muerte.

\section{SEgundo lugar: el Viaje}

«Pero mientras Él avanza victorioso y triunfador con su cuerpo resucitado de la muerte, algunas potencias celestes dicen: ¿Quién es éste que viene de Edón, todo vestido de rojo, tan lleno de fuerza?» (Is 63,1). "Y los ángeles que lo escoltan dicen a los custodios de las puestas celestiales: “¡Príncipes, levantad vuestras puertas! Alzaos, puertas eternas, va a entrar el Rey de la gloria!" ${ }^{27}$. Tal vez este tono amenazador lo asociamos poco con determinados momentos de la historia y del arte medievales. Pero el hecho es que en torno al año mil ha madurado una conciencia de fin del mundo que empieza a ser representada en los portales de las iglesias hasta en los lugares más recónditos de la Europa del momento. El viaje, por eso, es para nosotros el segundo lugar celeste de la filosofía neoplatónica medieval.

La expresión epigráfica latina super astra, vuelve a repetirse, otra vez emparejada al hecho de la muerte corporal, aunque ahora más cercana al contexto del viaje y divinización del alma. No deja de ser un lugar común de la literatura filosófica del pensamiento neoplatónico. Platón, con su pitagórica asunción de la naturaleza astral de las almas y sus mitos escatológicos, es en gran parte el responsable de la elaboración literaria de este lugar celeste ${ }^{28}$.

La metafísica cristiana es heredera directa de la concepción grecolatina que se inaugura con la visión del ser humano como ente dual en la filosofía presocrática. Sistematizada y completada por Platón, desemboca en el corpus teórico del cristianismo previa transición gnóstica en el sistema neoplatónico. La noción de alma inconsistente, de esencia ígnea, que se propaga por dimanación, se mantiene invariada y apenas evoluciona sustancialmente a lo largo de la historia de la filosofía antigua. A pesar de ello, en la cultura medieval, quizá por incapacidad conceptual, las ánimas son descritas en dimensiones físicas ${ }^{29}$.

27 Orígenes, Comentario a los Salmos 67,19; Comentario a Juan VI, 56; XIX, 21.

28 En concreto su mito de Er fue muy comentado a partir del siglo II d.C. Encabeza la lista de estos comentaristas Numenio, seguido por Gayo, Albino, Máximo de Nicea, Harpocración, Euclides y Porfirio. Cf. Pérez Jiménez, A. «El viaje sidéreo de las almas: origen y fortuna de un tema clásico en Occidente.» Fortunatae: Revista canaria de filología, cultura y humanidades clásicas 5 (1993): 101, nota 1. Sobre sus orígenes orientales, ver nota 2.

29 Merino Castrillo, Juan El viaje al más allá en las literaturas hispánicas hasta Berceo. Instituto de Estudios Riojanos, 2009: 165. 
En Ripoll, san Pedro y san Pablo figuran sobre los ensanchamientos de la portada $^{30}$. En el fuste de las tres columnas del lado izquierdo destaca la figura descabezada del apóstol Pedro que sostiene una especie de filacteria. A pesar del desgaste sufrido por la piedra, aún se alcanza a leer con dificultad una inscripción, nuevo lugar celeste del pensamiento neoplatónico: «Pedro abre el camino y conduce al pueblo hacia las estrellas» (Petrus iter pandit et plebs ad sidera scandit $)^{31}$. El mismo sentido filosófico de traslación o viaje se produce en el pórtico de acceso a la iglesia de San Trófimo de Arles ${ }^{32}$, donde también Pedro acoge al fiel sobre la pared izquierda del porche con estas palabras escritas: «Pedro conduce al cielo a aquellos cuyos pecados han sido redimidos»: Criminibus demptis reserat petrus astra ${ }^{33}$ redemptis ${ }^{34}$.

Algo similar ocurre con los evangelistas que aparecen en la decoración de San Martín de Fonollar, también del siglo XII ${ }^{35}$. Junto a sus símbolos iconográficos se leen cuatro versos tomados del Carmen Paschale del poeta Sedulio (c. 850) $)^{36}$ : Mateus natum de virgine predicat agnum; Marcus ut alta fremit vox per deserta leonis; Iura sacerdotis Lucas tenet ore iuvenci; more volans aquilae verbo petit astra Iohannes ${ }^{37}$. Las inscripciones alusivas a Mateo, Marcos y su misión evangelizadora, son testimoniadas también en San Salvador de Casesnoves; la referente a Marcos recoge la misma versión del verso de Sedulio, presente en Fonollar. Tiene singular interés el texto referente a Mateo, puesto que difiere del original del poeta carolingio, que dice: hoc Matheus agens hominem generaliter implet. La presencia de la misma versión, diferente del original en ambas, en las iglesias de Fonollar y de Casesnoves refleja un origen común a ambos textos escritos.

El concepto de viaje astral hunde sus precedentes en el pitagorismo, el hermetismo y el estoicismo y se sostiene sobre el argumento filosófico de que el

30 Cf. Altman, Charles F. «The medieval marquee: Church portal sculpture as publicity.» The Journal of Popular Culture 14, no. 1 (1980): 37-46.

31 Ainaud de Lasarte, J. Catalogne romane, La-Pierre-qui-Vire, 1994: 129. Citado en: AngHeben, Marcel. «Apocalypse XXI-XXII et l'iconographie du portail central de la nef de Vézelay», Cahiers de civilisation médiévale, 163 (1998): 228.

32 Ver, por ejemplo, Thirion, Jacoues. Saint-Trophime d'Arles. Société française d'archéologie, 1979.

33 Mientras que los escritores griegos distinguen entre astro "astro aislado» (Hesíodo) y astros «constelación», como recuerda Macrobio (Somn. Scip. I, 14, 21), el término latino ha tomado los valores semánticos del uno y del otro. Aquí, utilizado en plural, toma el sentido de «constelación». En conclusión, desde el punto de vista del lenguaje científico, la distinción entre "astro aislado» y "constelación» no es de una importancia fundamental en los manuscritos del monasterio de Ripoll como el MS ACA Ripoll 74, del siglo XI.

34 Rouquette, Jean Maurice. Provence romane, La-Pierre-qui-Vire, 1974: 281-282.

35 Ainaud i de Lasarte, Joan. «El Darrer Congrés Arqueològic de França.» Butlletí de la Societat Catalana d'Estudis Històrics 3-4 (2005): 69.

36 Cf. Esposito, MARio. «The Latin Writers of Mediaeval Ireland.» Hermathena 14, no. 33 (1907): 519-529.

37 Carmen Paschale, I, v. 358: «Juan, volando como el águila, por la virtud del verbo, alcanza las alturas celestes». Fernández, SANTIAgo. La epigrafía latina medieval: 199. 
alma tiene la misma naturaleza que los astros, puesto que las almas son efecto del principio ígneo que da vida al mundo. El alma se compone de ese aire inflamado (la res flabilis de Prudencio) ${ }^{38}$, que asciende por efecto del calor. Los uiri sancti son transportados por otros seres de consistencia análoga, mientras escuchan la música celeste, contrapunto de lo cristiano, de la armonía cósmica de las esferas ${ }^{39}$. A lo largo de este tránsito, aparecen, dice Dionisio Areopagita ${ }^{40}$ «seres con extremidades, o criaturas con muchas cabezas, imágenes caninas o leones y águilas de pico curvo, criaturas voladoras con triples alas, irradiaciones celestiales, formas a modo de ruedas, caballos de formas variadas, el Sagitario armado y todo tipo de símbolos formales y sagrados que nos ha llegado a través de la tradición ${ }^{41}$. Es la metafísica de la disimilitud la que opera en el viaje ${ }^{42}$.

Tal vez en relación a esta disimilitud, se ha dicho que lo grotesco nace en la memoria del monje metido en su claustro ${ }^{43}$. En el juego de elementos estéticos que abarca lo monástico, dos elementos juegan un papel fundamental: la imaginación y el silencio. La retórica cuenta con la imaginación, mientras que la meditación requiere, para la elaboración de imágenes interiores, del silencio. En este contexto, el monje que se aparta del mundo tiene una necesidad de «ver» sus pensamientos, que deben estar organizados estéticamente en esquemas

38 Sed tradita forma est humanis quae nota animis daret intellectum,/ut per corpoream speciem plasmasse feratur/corporis effigiem./sic est plasmata vicissim flatu incorporeo res flabilis, oris et esse fertur opus, tenuis per quod constructa refulsit forma animae atque rudi factam se munere sensit. Apotheosis. Hymnus de Trinitate v. 863-865. He utilizado la edición Prudentius. With an English translation by H. J. Thomson. (Loeb Classical Library.) Vols I (1949) y II (1953). London: Heinemann. El subrayado es nuestro.

${ }_{39}$ En la literatura cristiana, ya Tertuliano en De anima $(3,26)$, compuesto a principios del siglo III, define el tránsito como un vuelo, pero la representación zoomórfica del alma es un águila, relacionada con la famosa metamorfosis de Zeus: Quommodo igitur illa anima, quae terris inhaerebat, nullius sublimitatis, nullius profunditatis, intrepida, ...aeri postea insultabit in aquila? Orígenes concibe la vida monástica (y, en general, la vida espiritual) como una ascensión ardua, llena de esfuerzo y sufrimiento, pero, al mismo tiempo, extraordinaria, puesto que conduce a las alturas de la theoria, a la plenitud de la gnosis, a la unión mística con el logos. Para alcanzarla, el cristiano ha de despojarse de todo lo mundano, empezando por el cuerpo, practicando un radical y absoluto contemptus mundi. Nótese cómo, en estos dos autores cristianos, se hace transparente el proceso de fusión de paganismo y cristianismo. Tertuliano reutiliza la cultura pagana en aras de la nueva fe; Orígenes, por su parte, se apropia de la teoría neoplatónica para interpretarla en clave cristiana. MERINo CASTRILlo, JUAN El viaje al más allá en las literaturas hispánicas hasta Berceo. Instituto de Estudios Riojanos, 2009: 166.

40 Citado por Cook, Sir Theodore Andrea, and Hensher, Philip. Old Provence. Interlink Publishing Group Incorporated, 1905, 2: 79.

${ }_{41}$ Ver Sti. Dionisii De Theologia Simbolica, ep. I, ad Titum Pontificem. Citado, ya en 1899 , por Scott, LeAder. «Cathedral Builders: the Story of a Great Masonic Guild (1899).» Reprint, Whitefish, MT: Kessinger (2003): 76.

42 Cf. Miernowski, JAN. Le dieu néant: théologies négatives à l'aube des temps modernes. Vol. 82. Brill Academic Pub, 1998. Especialmente: 9-21.

43 Domínguez Torres, Mónica Frames for Conversion: The Assimilation of Native Motifs in the Monastic Decoration of New Spain (1540-1580). University of Toronto, 2004. 
pictóricos, mezclando medios verbales y visuales ${ }^{44}$. Son los útiles que darán el ímpetu necesario a la expresión de la memoria domini como distintiva del apartamiento del mundo y la contemplación. Filosóficamente, el viaje es la fragua de lo grotesco, que luego la Modernidad utilizará como arma arrojadiza de la ilusión en busca de la similitud. Lo grotesco medieval no deja de ser una elaboración estética del viaje como lugar celeste, por vía mnemotécnica, de la disimilitud ${ }^{45}$.

\section{Tercer lugar: el Juicio}

La expresión astra, en el contexto de la estética medieval, se refiere también a la Segunda venida de Cristo o Día del Juicio ${ }^{46}$, en que una serie de signos aparecen en el cielo ${ }^{47}$. En este sentido, hay fuentes que, aunque distintas entre sí, tocan el mismo tema escatológico, y cronológicamente convergen a fines de la Edad Media en la forma de los versos de la Sibila Eritrea ${ }^{48}$, que recoge san Agustín en la Ciudad de Dios ${ }^{49}$. Además de los acrósticos de Agustín ${ }^{50}$, también forman parte del Juicio como lugar celeste el Sermo de symbolo (de Quodvultdeus de Cartago) y los Sibyllorum verborum interpretatio de san Beda el Venerable (672-735), muy influyentes a lo largo del renacimiento carolingio. Pero no son éstos los únicos, porque ciertos doctores y prelados de la Iglesia como san Pedro Damián (1007-1072), Pedro el Confesor (†1178) o santo Tomás de Aquino (1225-1274) atribuyen a san Jerónimo (340-420) los versos sibilinos con los quince signos del Juicio final ${ }^{51}$.

44 Cf. Geary, Patrick J. «Monastic Memory and the Mutation of the Year Thousand.» Monks and Nuns, Saints and Outcasts: Religion in Medieval Society. Essays in Honor of Lester K. Little (2000): 19-36.

45 CARruthers, Mary. The craft of thought: Meditation, rhetoric, and the making of images, 400-1200. Vol. 34. Cambridge University Press, 2000.

461 Juan 2, 18.

47 Barcelona, ACA, Ripoll 106, fol. 92v.

48 Cf. Collins, John J. «Sibylline Oracles.» The Old Testament Pseudepigrapha 2 (1983): 317-472.

49 Cf. De civitate Dei, XVIII.23.

50 Cf. Bayless, Martha. Parody in the Middle Ages: the Latin tradition. University of Michigan Press, 1997.

51 En esencia, el tema del Juicio Final en la literatura pervive en la dramaturgia primitiva, también en Castilla y otros lugares. Véanse: De CAstillejo, CRistóbal. "Para la noche de Navidad», Obras, IV, edición y notas de Domínguez Bordona, Juan. Clásicos Castellanos, 1958: 178; Vicente, Gil. "Auto de la Sibila Casandra», Vicente, Gil. Obras dramáticas castellanas: Edición, estudio y notas de Thomas R. Hart. Vol. 156. Espasa-Calpe, 1962: 75; y DIEGo SÁNCHEZ DE BADAJOZ (segunda mitad del XVI), "Farsa de juegos de cañas», en Recopilación en metro, Libros de antaño, edición de D. V. Barrantes, Librería de los Bibliofilos, 1882. Véase también Darbord, Michel. La Poesie religieuse espagnole des rois catholiques a Philippe II.Paris 1965:(Floch). 462 S. $8^{\circ}$. Vol. 4. Centre de recherches de l'Institut d'études hispaniques, 1965: 130. 
Efectivamente, Quodvultdeus de Cartago, por un tiempo confundido con san Agustín, escribe: Praedictio impleta qua elatione ceciderit diabolus (credita tantum) Esaias propheta de eo: dicebas, ait, in corde tuo: in caelum ascendam super astra Dei, exaltabo solium meum, sedebo in monte testamenti (...), «sobre las estrellas de Dios exaltaré mi trono, me sentaré en el monte de la Alianza» ${ }^{52}$. Esta vez se trata de un lugar celeste que remite al lugar filosófico del Juicio, aunque pueda solaparse con los lugares litúrgicos de la música sacra ${ }^{53}$.

Los manuscritos con versos Sibilinos, que conocemos en archivos españoles, son de un período muy temprano. Dos de ellos pertenecieron al monasterio benedictino de Santa María de Ripoll que, fundado en 879, enseguida se transformó en un importante centro cultural ${ }^{54}$. El más antiguo es una original miscelánea científica y sagrada del siglo $\mathrm{x}^{55}$. Otro de Ripoll, que reproduce los versos de la Sibila, de los siglos x y xI, es la Sibyllorum verborum interpretatio ${ }^{56}$. A su vez, el código tarraconense de hacia el año $800^{57}$ sugiere que en la Marca Hispánica, hoy Cataluña, el texto de Beda y el Sermo de symbolo, con sus respectivos versos sobre el Juicio final, eran conocidos desde muy pronto. El cuarto manuscrito que conocemos, perteneciente al grupo hispánico, procede de Castilla y es un Homiliarium copiado en el monasterio de san Baudelio de Berlanga (Burgos), una de las joyas del arte mozárabe, del año $953^{58}$. Todos estos trabajos son manuscritos musicales en los que la letra constituye, por vía literaria, una importante referencia al Juicio final como típico lugar celeste del sistema filosófico neoplatónico, de tradición incluso anterior a la filosofía cristiana $^{59}$.

No conocemos en qué momento este tipo de versos empiezan a formar parte de la liturgia, al menos de forma generalizada. Sí sabemos que un Ordo romanus anterior al 1143 dice, en alusión a la liturgia papal para Navidad: In vigilia Natalis Domini ad Matutinum (...) Quarta lectio sermo sancti Augustini Vos inquam convenio, o iudaei, in quarta cantantur sibyllini versus Iudicii signum: tellus sudore madescet ${ }^{60}$. Significa esto que en el segundo tercio del siglo XII el Sermo de symbolo con los versos de la Sibila eran cantados, y costumbre asentada en las lecciones de los maitines de Navidad en la capilla del Papa, lo cual con ciertas variaciones empezó a transformarse en práctica habitual

52 Quoduultdeus, Liber promissionum et praedictorum Dei Cl. 0413, Dimidium temporis, 2,1 .

53 Cf. Wallace, Robin. «The Role of Music in Liturgical Drama: a Revaluation.» Music \& Letters (1984): 219-228.

54 Cf. Español, Francesca. «Ianua Coeli: Monumental Romanesque doorways on the Iberian Peninsula.» Catalan Historical Review 4 (2011): 145-147.

55 Barcelona, ACA, Ripoll 106, fol. 92v.

56 Barcelona, ACA, Ripoll 151, fol. 37.

57 Paris, BNP, Lat. 8093, fols. 35v-36.

58 Córdoba, AC, ms. 1.

59 Mantenemos el uso que de esta expresión se ha hecho en: Gilson, Etienne. History of Christian philosophy in the Middle Ages. Random house, 1955.

60 PL LXX-VIII: 1031. 
en ese período ${ }^{61}$. IV. Cum aperta caeli astra,/Usque ad terminos terrae/Caeperit turba canere,/Sancti arcangeli Dei/Voce magna proclamare,/Et electos congregare. «Una vez abiertos los cielos, la multitud se precipita a los confines de la tierra. Mientras, los arcángeles de Dios proclaman a los elegidos, con una gran voz» ${ }^{62}$.

Hemos visto hasta ahora el uso de la expresión astral, sideral o celeste en el arte, la literatura y la música sacra. A veces se refiere a connotaciones simbólicas sagradas; otras puede tomar tintes incluso científicos ${ }^{63}$. Es evidente que en las distintas formas de utilizar la expresión "más allá del cielo» el epígrafo incurre en un cierto formulismo. Es en esta misma época cuando Juan Escoto Eriúgena (c. 815-c. 877), el más hábil traductor conocido de la obra de Dionisio el Areopagita ${ }^{64}$, irrumpe en la literatura metafísica y aporta una nueva cosmovisión estética ${ }^{65}$. Aquel monje irlandés de la corte de Carlos el Calvo (823-877), contemporáneo de Rábano Mauro (c. 780-856), traduce textos pero también mentalidades. Es el traductor, en el siglo Ix, de «lo griego» a «lo latino», de la creatividad oriental al rigor occidental.

Un nuevo sentido del orden irrumpe en Europa con el renacimiento de los textos del Escoto, quien es transmisor, a su vez, de la versión más mística de Agustín, de Máximo el Confesor y, sobre todo, del Corpus Areopagiticum ${ }^{66}$. Fundamentalmente, se difundirán hasta el último rincón de esta nueva Europa por la vía de la prédica homilética escrita en prosa rimada y conocida como la $\mathrm{Ho}$ milía al Prólogo del evangelio de san Juan. La así llamada Vox spiritualis aquilae, será leída y aclamada en la noche de Navidad como un canto al Cristo luz. Iconológicamente, remite al mismo Logos que habrá ocupado el epicentro de la iconografía medieval durante quinientos años de historia, y que fue predicado por san Pablo en el Areópago, donde la piedad popular imagina a Dionisio convertido al cristianismo. Aquí, efectivamente, es inevitable referirse al lugar celeste de la iconografía de la maiestas domini rodeada de una almendra de luz ${ }^{67}$.

61 Sobre este tema ver el trabajo fundamental de GómEz, Maricarmen. «From the Iudicii Signum to the Song of the Sybil: Early Testimony.»Hispania Vetus: Musical-Liturgical Manuscripts from Visigothic Origins to the Franco-Roman Transition (9th-12th Centuries) (2007): 159-173.

62 Versus de die iudicii, IV y VI, en: Fernández, Santiago. La epigrafía latina medieval en los condados catalanes (815-circ. 1150). Castellum, 2003: 164.

63 Ver, por ejemplo, EAstwood, Bruce Stansfield. «Johannes Scottus Eriugena, sun-centred planets, and Carolingian astronomy.» Journal for the History of Astronomy 32 (2001): 281-324.

64 Copeland, Rita. Rhetoric, Hermeneutics, and Translation in the Middle Ages: Academic Traditions and Vernacular Texts. Vol. 11. Cambridge University Press, 1995, especialmente: 52.

65 Eriugena, Johannes Scotus. "Translator, Not Expositor'.» Excerpted from prologue to translation of De caelesti hierarchia by Pseudo-Dionysius the Areopagite, translated \& cited by Copeland (1991): 52.

66 Moran, Dermot. The philosophy of John Scottus Eriugena: a study of idealism in the Middle Ages. Cambridge University Press, 2004: 52-53, etc.

67 Siguen vigentes las obras: VAN DER MEER, FrederIK. Maiestas Domini: théophanies de l'Apocalypse dans l'art chrétien. 13. Pontificio istituto di archeologia cristiana, 1938 y CAPIZZI, Carmelo. Pantokratōr: (saggio d'esegesi letterario-iconografica). 170. Pont. Institutum Orientalium Studiorum, 1964. 
Más tarde, aunque siguiendo la tradición escenográfica medieval ${ }^{68}$, las Octavas del poeta español Francisco de Aldana (1537-1578) sitúan en el lugar que le corresponde al Paraíso en "alto» (v.5) ${ }^{69}$. En ese lugar elevado, y a modo de telón de fondo, viene representado el Cielo, propiamente dicho, al pie del cual se encuentra el trono que ocupará Dios en su papel de juez universal. En este caso, el Cielo viene caracterizado como lugar especialmente luminoso, gracias a la «maquina de luz» (v.11) que los «espíritus alados» (v.10) «van componiendo».

El poeta hace explícita mención a la tramoya como técnica puesta al servicio del teatro medieval para conseguir un espectacular efecto lumínico que materializa en escena el principio de lo maravilloso. Forma parte también del juego tramoyístico la presencia de los astros, alusión, o al menos reminiscencia, a los fastuosos decorados medievales que solían estar levantados sobre un escenario octogonal y cuyas paredes revestidas con damascos y telas de raso, llevaban un sol y una luna que se oscurecían artificiosamente ${ }^{70}$. Otro lugar celeste y filosófico que se corresponde con la disyuntiva - epistemológica y teológica- del Juicio.

El efecto de espectáculo que el autor consigue en las $\operatorname{Octavas}^{71}$, fundamentalmente a través de la escenificación mental a la que somete el tema y a la introducción de unos personajes-actores, es completado por una serie de signos auditivos, visuales e incluso olfativos referidos especialmente al lugar del infierno: el «terrible estruendo» con el que se abre el infierno, los «alaridos» de los condenados y torturados que suenan dentro, el sonido aterrador de la trompeta anunciadora del comienzo del Juicio, el «fuego horrendo», los «montes de humo», la «niebla» que exhala el «cavernoso centro». Todos esos efectos sensoriales recuerdan de forma clara la escenografía medieval utilizada en la representación del tema del Juicio final ${ }^{72}$.

Comprendemos, por tanto, que la cuestión del Juicio, desde el punto de vista de los lugares celestes, es también un lugar filosófico y epistemológico que comparte el sistema de las artes y la literatura, porque constituye una experiencia estética conectada con la noción de Juicio final en el pensamiento neoplatónico medieval ${ }^{73}$.

68 Sheingorn, Pamela. «For God is such a Doomsman: Origins and Development of the Theme of Last Judgment.» Homo, Memento Finis: The Iconography of Just Judgment in Medieval Art and Drama, Early Drama, Art, and Music, Monograph Ser 6 (1985): 40-46.

69 Cito por la edición de Lara Garrido, José. Francisco de Aldana: Poesía castellana completa, Cátedra, 1985.

70 Gonź́lez Martínez, Lola. «Iconografía y dramaturgia medieval en las "Octavas sobre el Juicio Final" de Francisco de Aldana», Actas del XII Congreso de la Asociación Internacional de Hispanistas 21-26 de agosto de 1995, Birmingham: 257-265. Department of Hispanic Studies, 1998: 260.

71 Cf. Ferraté, Juan. «Una muestra de poesía extravagante. Las octavas sobre Efectos de amor de Francisco de Aldana.» Dinámica de la poesía: ensayos de explicación, 1952-1966, 2 (1962): 215-43.

72 GonZÁlez, LoLA. «Iconografía y dramaturgia medieval...»: 262.

73 Cf. VIsser, Derk. Apocalypse as Utopian Expectation (800-1500): The Apocalypse Commentary of Berengaudus of Ferrières and the Relationship Between Exegesis, Liturgy, and Iconography. Vol. 73. Brill, 1996. 


\section{Cuarto y Último lugaR: la Divinización}

La hermenéutica de los lugares celestes en el neoplatonismo medieval convive con el análisis de la Esencia divina como negación de la luz, al estilo del Pseudodionisio y, más tarde, de Juan Escoto Eriúgena. Arte, filosofía y teología vuelven a ir de la mano en otra obra de arte como el antiguo tapiz de la Creación, que se conserva de la catedral de Gerona, donde el ángel de las tinieblas lleva una antorcha de luz oscura y el ángel de la luz la lleva de luz brillante. Puede verse esta dualidad como Tinieblas-Luz, Ocultamiento-Manifestación, doble aspecto de una única Realidad, o juego de un espejo donde la Imagen tiene la esencia de Lo Que se mira, la Tiniebla invisible ${ }^{74}$.

Por esta línea, nada puede decirse, en sentido literal, de la absoluta Tiniebla divina, si no es por su antítesis, la Luz que es el Hijo: el Hombre divinizado como autoconocimiento de Dios. La paradoja consiste en que el ángel, símbolo de la manifestación, muestra aquí la No-Manifestación: Tinieblas y Nada. Equivale a la denominada vía o teología negativa, expresión que no debe entenderse literalmente porque hay que dar la razón al Pseudodionisio, en relación al conocimiento de Dios por vía negativa, cuando dice que «por el libre, absoluto y puro apartamiento de ti mismo y de todas las cosas, arrojándolo todo y del todo, subirás espiritualmente hasta el rayo de tiniebla de la divina Supraesencia» ${ }^{75}$.

No es posible entender los lugares celestes del neoplatonismo, sin tener en cuenta el sentido filosófico del Retorno. Hacen falta referentes metafísico-teológicos para desentrañar el significado de esa salida y retorno de la imagen de la majestad de Dios. Por eso, en este contexto, el concepto de théosis o divinización del alma ${ }^{76}$, es clave y debe ir más allá del puro simbolismo de las imágenes. En su Comentario al Evangelio de Juan ${ }^{77}$, Eriúgena utiliza la expresión Descendit enim verbum in hominem ut, per ipsum, ascenderet homo in deum, es decir, «El Verbo ha descendido en el hombre de modo que, por Él, el hombre sea elevado a Dios $»^{78}$. En la théosis, entendida como divinización de la creatura, no hay espacio para la metáfora. Es literalmente como el Verbo asume la naturaleza humana y como ésta, en virtud de esa asunción, queda divinizada en la Persona de Cristo.

Siguiendo el texto, lo que en el evangelio de Juan es el Verbo hecho carne ${ }^{79}$, en el Comentario eriugeniano, pasado por la lógica de Marciano Capella ${ }^{80}$, la

74 García Renau, María Antonia. El tapís de la creació, símbol del Sagrat, Hogar del libro, 1993: 51.

75 Pseudodionisio Areopagita, «Teología mística» 1, 1000A, Pseudodionisio Areopagita, Obras completas, T. H. Martín y O. González de Cardenal, Madrid, Ed. Católica, 1990.

76 Ver, por ejemplo: Moran, Dermot. «Expounding Eriugena.»Irish Historical Studies 31, no. 122 (1998): 247-258.

77 E. Jeauneau, Jean Scot, Commentaire sur l'Évangile de Jean, Paris, Sources Chrétiennes, 180, Les Éditions du Clerf, 1972.

78 Johannes Scotus Erigena, Édouard Jeauneau. Homélie sur le prologue de Jean. Éditions du Cerf, 1969. 298A25-30.

79 Juan 1, 14.

80 Martianus Capella, De Nuptiis IV 397, ed. Martianus (Capella.), Adolfus Dick, and Jean Préaux. Martianus Capella. Teubner, 1969. 190-191. 
carne es hecha Verbo. Debemos pensar, conociendo el contexto, que al decir que la carne se hace Verbo, Eriúgena quiere significar que la naturaleza humana se libera del pecado al unirse a la gracia; estamos en el contexto del redditus: la vuelta de la imagen al origen, el retorno del facta est lux al fiat lux. Porque la expresión de Escoto no deja lugar a dudas: Et habitabit in nobis, hoc est conuersatum est inter nos homines ${ }^{81}$, Verbum habitabit in nobis, hoc est, naturam nostram possedit, "Y habitó entre nosotros, es decir, llega enmedio de nosotros, los hombres; el Verbo ha habitado en nosotros, o sea, ha tomado posesión de nuestra naturaleza» ${ }^{82}$.

El concepto de un Dios que sale de su Silencio (exitus) para crear un mundo perfecto, y que vuelve (redditus) redimiéndolo de su pecado, no es una especulación que se hace al observar, imaginativamente, por seguir con este ejemplo del mundo del arte, en la imagen del tapiz de la Creación ${ }^{83}$. El tapiz es un documento más que permite avalar una mentalidad que se dirige ideológicamente hacia este punto: por una parte, un Dios-Luz que, con una iluminación veterotestamentaria (Génesis) se patentiza mediante la creación de un mundo perfecto; y, por otra, un Cristo-(también) Luz que, neotestamentariamente (Prólogo de Juan), se teofaniza y remite a una segunda teofanía lumínica (la Parusía), que es la que se lee en el Apocalipsis de Juan. Textos eriugenianos filosóficos como el Periphyseon, poéticos como el Aulae sidereae ${ }^{84}$ (s. IX) o, más tardíamente, el De Luce de Grosseteste (s. XIII), forman parte de un marco cultural europeo que, ya desde época carolingia, propicia unas inercias estético-teológicas y un estatuto mental para toda una época marcada por un fuerte dinamismo cultural-religioso. Son, en última instancia, lugares filosóficos donde converge una mentalidad astral, sideral o, en el sentido más amplio, lugares celestes del neoplatonismo medieval.

81 Hay un precedente similar en Alcuino: Et verbum, inquit, caro factum est et habitauit in nobis. Quod est dicere: Et filius dei homo factus est et inter homines conuersatus est (ALCUINo, Commentaria in Iohannis euangelium, I, I; PL 100, 748D).

82 Homélie sur le prologue de Jean, 298A31-33. Aquí el texto del Comentario concuerda con otro de la Homilia: Et habitabit in nobis, hoc est, naturam nostram possedit, ut suae naturae nos participet faceret (Homélie, 295C30). En el Periphyseon abunda en el lugar de esta inhabitación: Et quod est eius habitaculum? Nonne nostra natura, in qua per incarnationem habitare voluit? Audi euangelistam: Et uerbum, inquit, caro factum est et habitabit in nobis, PL 122, 1003B5-9).

83 Puigarnau, Alfons. "Fiat Lux": Iconology and Theology of Time in Medieval Catalonia», Jaritz, Gerhard-Moreno-Riano, Gerson (eds.) Time and Eternity. The Medieval Discourse, International Medieval Research, Volume 9. Turnhout, Brepols 2003: 427-450.

84 Texto de la consagración de la capilla de Carlos el Calvo en Compiègne, consagrada el 877 y a la que va dedicado el poema Aulae sidereae. Traducción de Francisco Socas en la sección de «Traducciones e inéditos» de ER Revista de filosofía 3, (1986): 129-134, cuyo original es el Cantabrigensis Collegii Corporis Christi codex 223, publicado por L. Traube en Iohannis Scotti Carmina in M. G. H. poet. lat. aevi carolini, Berolini, 1896, IX: 550-552. Ver también M. FoussaRd, «Aulae sidereae. Vers de Jean Scot au Roi Charles», Cahiers Archéologiques XXI (1971): 81-88. 


\section{BiBLIOGRAFÍA}

Ainaud de Lasarte, Joan. «El Darrer Congrés Arqueològic de França», Butlletí de la Societat Catalana d'Estudis Històrics 3-4, 2005.

- Joan. Catalogne romane, La-Pierre-qui-Vire [Yonne], Zodiaque, 1994.

Almagro, Martín. Las inscripciones ampuritanas, griegas, ibéricas y latinas. Barcelona, Departamento de Barcelona del Instituto Rodrigo Caro de Arqueología del Consejo Superior de Investigaciones Científicas, 1952.

Altman, Charles F. «The medieval marquee: Church portal sculpture as publicity.» The Journal of Popular Culture 14, no. 1, 1980, 37-46.

Angheben, Marcel. "Apocalypse XXI-XXII et l'iconographie du portail central de la nef de Vézelay», Cahiers de civilisation médiévale, 163, 1998.

Bayless, Martha. Parody in the Middle Ages: the Latin tradition, Ann Arbor, University of Michigan Press, 1997.

Burnett, Charles. «Arabic into Latin: the reception of Arabic philosophy into Western Europe.» The Cambridge Companion to Arabic Philosophy, Cambridge University Press, 370-404.

Capizzi, Carmelo. Pantokratōr: saggio d'esegesi letterario-iconografica. 170. Roma, Pont. Institutum Orientalium Studiorum, 1964.

Carruthers, Mary. The craft of thought: Meditation, rhetoric, and the making of images, 400-1200. Vol. 34. Cambridge University Press, 2000.

Catalunya Romànica, Barcelona, Enciclopèdia catalana, 1990, 10, 197-201; vol. 22, 183-185.

Collins, John J. «Sibylline Oracles.» The Old Testament Pseudepigrapha 2, 1983, 317-472.

Cook, Sir Theodore Andrea-Hensher. Old Provence. 2 vols. Oxford, Interlink Publishing Group Incorporated, 1905.

Cooper, Adam G. The Body in St. Maximus the Confessor: Holy Flesh, Wholly Deified, Oxford Early Christian Studies, Oxford, Oxford University Press, 2005.

Cooper, Charles Gordon. An introduction to the Latin hexameter. Melbourne and London, Macmillan, 1952.

Copeland, Rita. Rhetoric, Hermeneutics, and Translation in the Middle Ages: Academic Traditions and Vernacular Texts. Vol. 11. Cambridge University Press, 1995.

Darbord, Michel. La Poesie religieuse espagnole des rois catholiques a Philippe II.-Paris 1965:(Floch). 462 S. $8^{\circ}$. Vol. 4. Paris, Centre de recherches de l'Institut d'études hispaniques, 1965.

De Castillejo, Cristóbal. «Para la noche de Navidad», Obras, IV, edición y notas de Domínguez Bordona, Juan. Madrid, Clásicos Castellanos, 1958.

De Molins, Antonio Elías. Bibliografía histórica de Cataluña: Preliminares, numismática, epigrafía, colecciones diplomáticas, sigilografía. Imp. M. Marfany. Lib. Victoriano Suarez. Madrid, 1902.

Domínguez Torres, Mónica. Frames for Conversion: The Assimilation of Native Motifs in the Monastic Decoration of New Spain (1540-1580). University of Toronto, 2004.

Eastwood, BRuce Stansfield «Johannes Scottus Eriugena, sun-centred planets, and Carolingian astronomy.» Journal for the History of Astronomy 32, 2001, 281-324.

EsPañol, Francesca. "Ianua Coeli: Monumental Romanesque doorways on the Iberian Peninsula.» Catalan Historical Review 4, 2011, 145-147.

Esposito, MARIo. «The Latin Writers of Mediaeval Ireland.» Hermathena 14, no. 33, 1907, 519-529. 
Fernández, Santiago. La epigrafía latina medieval en los condados catalanes, 815-circ. 1150). No. 11. AC, Madrid, Castellum, 2003.

FERRATÉ, JuAN. «Una muestra de poesía extravagante. Las octavas sobre Efectos de amor de Francisco de Aldana.» Dinámica de la poesía: ensayos de explicación, 1952-1966, 2, 1962, 215-43.

Ferretti, Silvia. Cassirer, Panofsky, and Warburg: symbol, art, and history. Yale University Press, 1989.

FitA, Fidel. «Epigrafía romana. Colección de artículos (1883)», Kessinger Publishing Reprints, Whitefish MA, 2010, 40-42.

Foussard, Michel. "Aulae sidereae. Vers de Jean Scot au Roi Charles», Cahiers Archéologiques XXI, 1971, 81-88.

García Renau, María Antonia. El tapís de la creació, símbol del Sagrat, Barcelona, Hogar del libro, 1993.

Geary, Patrick J. «Monastic Memory and the Mutation of the Year Thousand.» Monks and Nuns, Saints and Outcasts: Religion in Medieval Society. Essays in Honor of Lester K. Little, New York, Cornell University Press , 2000.

Gilson, Etienne. History of Christian philosophy in the Middle Ages. New York, Random house, 1955.

Gómez, Maricarmen. «From the Iudicii Signum to the Song of the Sybil: Early Testimony.» Hispania Vetus: Musical-Liturgical Manuscripts from Visigothic Origins to the Franco-Roman Transition (9th-12th Centuries) Madrid, Fundación BBVA, 2007, 159173.

GonZÁlez Martínez, Lola. "Iconografía y dramaturgia medieval en las "Octavas sobre el Juicio Final" de Francisco de Aldana», Actas del XII Congreso de la Asociación Internacional de Hispanistas 21-26 de agosto de 1995, Birmingham, Department of Hispanic Studies, 1998, 257-265.

Hart, Kevin. The trespass of the sign: Deconstruction, theology, and philosophy (Perspectives in Continental Philosophy vol. 13), Fordham University Press, 2000.

Holly, Michael Ann. Panofsky and the foundations of art history. Ithaca, New York, Cornell University Press, 1985.

Lara Garrido, José. Francisco de Aldana: Poesía castellana completa, Madrid, Cátedra, 1985.

Latina, Patrologia. «Jacques-Paul Migne.»Patrologiae cursus completus, Paris 1965 (1844), vol. 122.

Levi, Albert William. "Kunstgeschichte als Geistesgeschichte: The lesson of Panofsky.» Journal of Aesthetic Education, 1986 79-83.

Marquès Casanovas, Jaume. Girona Vella, Girona, s.e., 1979.

Martianus Capella. Adolfus Dick (ed.), Leizpig, Teubner, 1925. Reimpresión con una nueva introducción de Jean Préaux. Stuttgart, Teubner, 1969.

McEvoy, James. «The Metaphysics of Light in the Middle Ages.» Philosophical Studies Dublin 26, 1979, 126-145.

Merino Castrillo, Juan El viaje al más allá en las literaturas hispánicas hasta Berceo. Logroño, Instituto de Estudios Riojanos, 2009.

MieRnowski, JAN. Le dieu néant: théologies négatives à l'aube des temps modernes. Vol. 82. Leiden, Brill, 1998.

Minnis, Alastair J. Chaucer's Boece and the medieval tradition of Boethius. Chaucer Studies Vol. 18. Suffolk-New York, Boydell \& Brewer, 1993.

Moran, Dermot. «Expounding Eriugena.»Irish Historical Studies 31, no. 122, 1998, 247 258. 
- The philosophy of John Scottus Eriugena: a study of idealism in the Middle Ages, Cambridge University Press, 2004.

Pérez Jiménez, Aurelio. «El viaje sidéreo de las almas: origen y fortuna de un tema clásico en Occidente.» Fortunatae: Revista canaria de filología, cultura y humanidades clásicas 5, 1993.

Poster, Carol. "Silence as a Rhetorical Strategy in Neoplatonic Mysticism.» Mystics Quarterly, 1998, 48-73.

Prudentius. With an English translation by H. J. Thomson. Loeb Classical Library. Vols I (1949) y II (1953). London, Heinemann.

Pseudodionisio Areopagita, Obras completas, T. H. Martín y O. González de Cardenal, Madrid, Ed. Católica, 1990.

Puigarnau, Alfons. "Fiat Lux": Iconology and Theology of Time in Medieval Catalonia», Jaritz, Gerhard-Moreno-Riano, Gerson (eds.) Time and Eternity. The Medieval Discourse, International Medieval Research, Volume 9. Turnhout, Brepols 2003, 427-450.

Quoduultdeus, «Liber promissionum et praedictorum Dei», Opera, R. Braun (ed.). Corpus Christianorum Series Latina 60, Turnhout, 1976, 1-223.

Robinson, Douglas. Western Translation Theory from Herodotus to Nietzsche, Manchester, St Jerome Press, 1997.

Rouquette, Jean Maurice. Provence romane, La-Pierre-qui-Vire, Zodiaque, 1974.

SÁnchez de Badajoz, Diego. "Farsa de juegos de cañas», Recopilación en metro, Libros de antaño, edición de D. V. Barrantes, Madrid, Librería de los Bibliófilos, 1882.

Scott, Leader. "Cathedral Builders: the Story of a Great Masonic Guild, 1899.» Reprint, Whitefish, MA, Kessinger, 2003.

Scottus Eriugena, Johannes. "Carmina», Monumenta Germaniae Historica, Poetae Latini Aevi Carolini, L. Traube (ed.), Berolini, 1896, IX.

- Aulae sidereae. Traducción de Francisco Socas en la sección de «Traducciones e inéditos» de ER Revista de filosofía 3,, 1986, 129-134.

- Édouard Jeauneau (ed.). Homélie sur le prologue de Jean. Sources chrétiennes, Textes latins $\mathrm{N}^{\circ}$ 151. Paris, Éditions du Cerf, 1969.

Sheingorn, Pamela. «For God is such a Doomsman: Origins and Development of the Theme of Last Judgment.» Homo, Memento Finis: The Iconography of Just Judgment in Medieval Art and Drama, Early Drama, Art, and Music, Monograph Serier 6, 1985, 40-46.

Thirion, Jacoues. Saint-Trophime d'Arles. Paris, Société française d'archéologie, 1979.

VAN DER MEer, FrederiK. Maiestas Domini: théophanies de l'Apocalypse dans l'art chrétien. Volumen 13 de Studi di antichità cristiana, Roma, Pontificio istituto di archeologia cristiana, 1938.

Vicente, Gil. "Auto de la Sibila Casandra», Vicente, Gil. Obras dramáticas castellanas: Edición, estudio y notas de Thomas R. Hart. Vol. 156, Madrid, Espasa-Calpe, 1962, 75.

VillanueVa, Jaime. Viage literario a las iglesias de España. Vol. 15. Madrid, Imprenta Real, 1766-1824.

VISSER, DERK. Apocalypse as Utopian Expectation (800-1500): The Apocalypse Commentary of Berengaudus of Ferrières and the Relationship Between Exegesis, Liturgy, and Iconography. Vol. 73. Leiden, Brill, 1996.

Wagner, Richard. Parsifal (Libreto). Madrid, Libros del Innombrable, 1999.

Universidad Internacional de Cataluña

Alfons Puigarnau

alfonsp@uic.es

[Artículo aprobado para publicación en noviembre de 2013] 